\title{
Comparative Efficacy and Safety of Intravenous Verapamil and Diltiazem for Rate Control in Rapidly Conducted Atrial Fibrillation and Atrial Flutter
}

$\mathrm{J}$ Gen Intern Med 35(12):3721-3

DOI: $10.1007 / \mathrm{s} 11606-020-06051-2$

() Society of General Internal Medicine 2020

\section{INTRODUCTION}

Beta-blockers and non-dihydropyridine calcium channel blockers (CCBs) are first-line therapy for heart rate (HR) control in atrial fibrillation (AF) and atrial flutter (AFL) . ${ }^{1}$ While diltiazem is used more frequently during inpatient practice than verapamil, ${ }^{2}$ a nationwide shortage of intravenous (IV) diltiazem starting in February $2018^{3}$ led to the more frequent use of alternative agents for rate control, including IV verapamil.

However, despite support from clinical practice guidelines, ${ }^{1}$ IV verapamil is prescribed much less frequently as a first strategy for rate control in AF/AFL. Lower utilization of verapamil compared with diltiazem naturally leads to an incomplete understanding about how the two CCBs compare in clinical practice. We performed a retrospective study to compare the efficacy and safety of these medications in controlling ventricular response inpatients with rapid AF and AFL in a single-center academic medical center.

\section{METHODS}

The University of Wisconsin-Madison Institutional Review Board approved this retrospective study. We included all patients aged 18 years or older with rapid AF or AFL who were treated with either IV verapamil or diltiazem infusion in the emergency department or inpatient setting from March 2017 to November 2018. Verapamil or diltiazem was administered at the attending physician's discretion without a predetermined treatment algorithm.

The primary endpoint was achieving of a ventricular rate $<$ $100 \mathrm{bpm}$ or a decrease in ventricular rate by $\geq 20 \%$ from baseline leading to termination of therapy. Consistent with prior studies, the primary safety outcome measures were

\section{Prior Presentation}

Poster presented at the University of Wisconsin, School of Medicine and Public Health Research Day; Madison, WI on June 14, 2019.

Received October 31, 2019

Accepted July 13, 2020

Published online July 24, 2020 bradycardia (HR $<60 \mathrm{bpm}$ ) and hypotension (systolic blood pressure $<90 \mathrm{mmHg}$ ). ${ }^{4}{ }^{5}$ Heart rate values were obtained irrespective of the underlying rhythm.

Results were presented as mean \pm standard deviation (SD) for quantitative variables and were summarized by absolute frequencies and percentages for categorical variables. Normality of data was analyzed using the Kolmogorov-Smirnoff test. Categorical variables were compared using the chi-square test or Fisher's exact test when the cells with expected count of less than 5 were observed or the total number is less than 40 . Quantitative variables were also compared with $t$ test. The trend of the change in study parameters was assessed by the baseline adjusted linear mixed effects model (LMM) and generalized linear mixed effects model (GLMM).

\section{RESULTS}

A total of 182 patients (104 men, 78 women) met the inclusion criteria. Of these, 152 patients received diltiazem and 30 received verapamil. There was no statistically significant difference in patient characteristics between the groups (Table 1).

There were no significant differences between the mean ventricular rates and blood pressures of the two groups at baseline. The HR was significantly decreased in both groups $(p<0.001)$ with treatment. The repeated measurement analysis of variance showed no statistically significant difference for HR and systolic blood pressure (SBP) at different times throughout the infusion period between the two medications (Fig. 1). The incidence of hypotension (SBP <90) or bradycardia $(\mathrm{HR}<60)$ was not significantly different between the two groups.

\section{DISCUSSION}

Diltiazem is the predominant agent for rate control in emergency departments (EDs) in the USA $(95.22 \%) .^{2}$ Both verapamil and diltiazem have similar mechanisms of action, contraindications, relative precautions, and proven comparative efficacy. This skewed prescription rate may reflect clinical experience and the notion that diltiazem has less negative inotropic effect than verapamil.

To our knowledge, this is the largest observational study comparing the effects of IV verapamil and diltiazem. Similar 
Table 1 Baseline Characteristics of Patients $(N=182)$ in Treatment Groups

\begin{tabular}{|c|c|c|c|}
\hline \multirow[t]{2}{*}{ Variable } & \multicolumn{2}{|l|}{ Medication } & \multirow[t]{2}{*}{$p$ value } \\
\hline & $\begin{array}{l}\text { Diltiazem (D) } \\
(N=152), n(\%)\end{array}$ & $\begin{array}{l}\text { Verapamil (V) } \\
N=\mathbf{3 0}, n(\%)\end{array}$ & \\
\hline Age (years), mean $\pm \mathrm{SD}$ & $70 \pm 13$ & $72 \pm 11$ & 0.42 \\
\hline Weight $(\mathrm{kg})$, mean $\pm \mathrm{SD}$ & $93.7 \pm 29.7$ & $87.4 \pm 19.8$ & 0.26 \\
\hline Male sex & $87(57.2)$ & $17(56.6)$ & 0.95 \\
\hline Female sex & $65(42.7)$ & $13(43.3)$ & \\
\hline Ejection fraction $(\%)$, mean $\pm \mathrm{SD}$ & $59.1 \pm 10.2$ & $60 \pm 11.1$ & 0.66 \\
\hline Ejection fraction $>50 \%$ & $129(88.3)$ & $28(93.3)$ & 0.75 \\
\hline Ejection fraction $<50 \%$ & $17(11.6)$ & $2(6.6)$ & \\
\hline \multicolumn{4}{|l|}{ Arrhythmia } \\
\hline Prior history of AF and AFL & $103(67.7)$ & $1860)$ & 0.46 \\
\hline New-onset AF and AFL & $49(32.2)$ & $12(40)$ & \\
\hline \multicolumn{4}{|l|}{ Underlying diseases } \\
\hline Smoking history & $76(50)$ & $14(46.6)$ & 0.73 \\
\hline Hypertension & $107(70.4)$ & $24(80)$ & 0.28 \\
\hline Hyperlipidemia & $78(51.3)$ & $20(66.6)$ & 0.12 \\
\hline Diabetes mellitus & $36(23.6)$ & $6(20)$ & 0.66 \\
\hline Coronary artery disease & $37(24.3)$ & $9(30)$ & 0.51 \\
\hline Peripheral artery disease & $9(6)$ & $2(6.6)$ & 0.69 \\
\hline Malignancy (active + in remission) & $33(21.7)$ & $7(23.3)$ & 0.84 \\
\hline COPD & $21(13.8)$ & $5(16.6)$ & 0.77 \\
\hline GFR, mean \pm SD & $68.8 \pm 24.5$ & $71.5 \pm 24.9$ & 0.62 \\
\hline Cerebrovascular accident & $8(5.2)$ & $1(3.3)$ & 0.99 \\
\hline
\end{tabular}

$A F$, atrial fibrillation; AFL, atrial flutter; COPD, chronic obstructive pulmonary disease; GFR, glomerular filtration rate
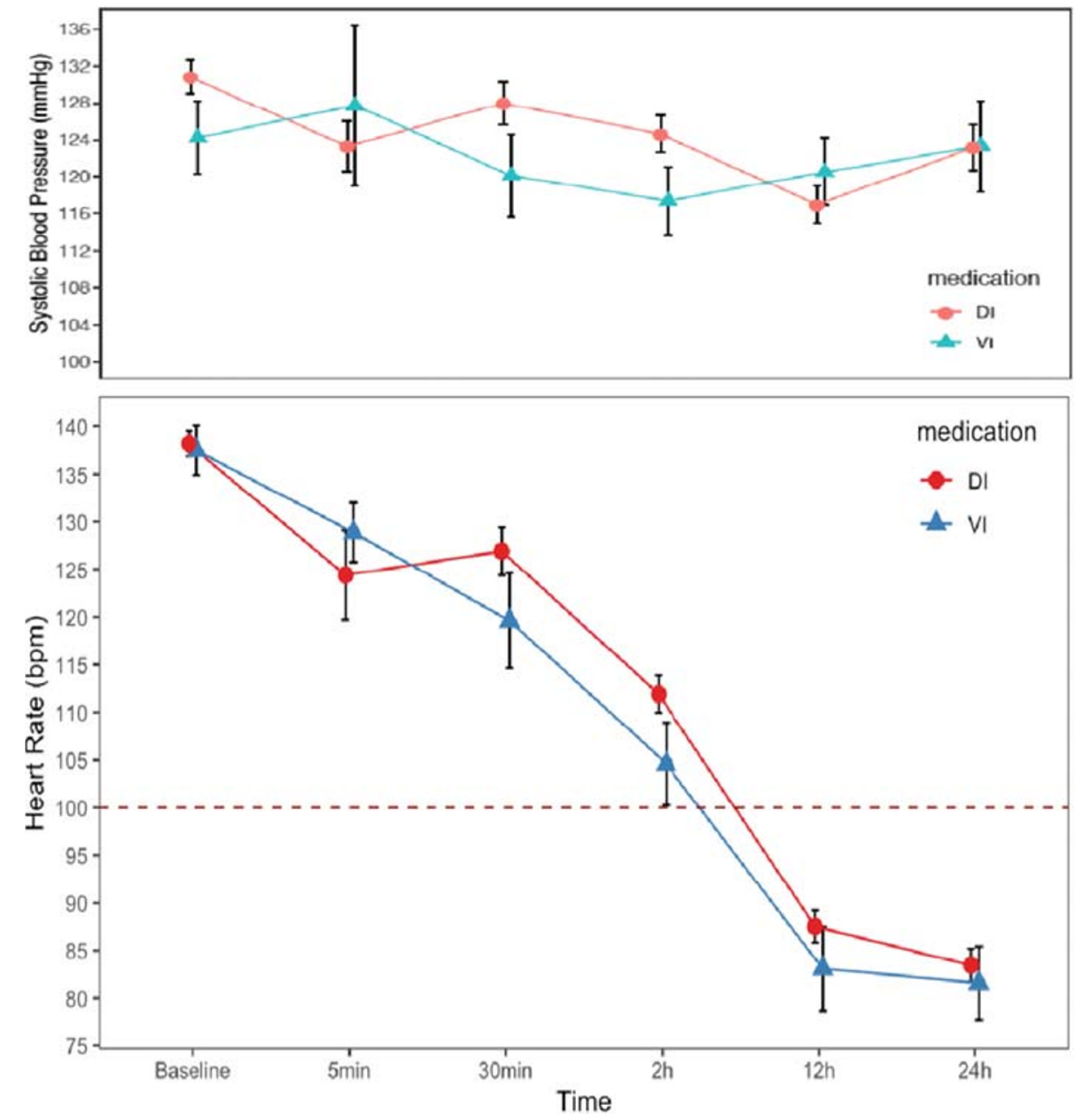

Figure 1 Systolic blood pressure (top panel) and ventricular rates (bottom panel) in relation to time during continuous intravenous verapamil and diltiazem infusions (mean $\pm \mathrm{SE}$ ). 
to prior work, ${ }^{6}$ our study demonstrates that diltiazem and verapamil were equally effective in controlling ventricular rates in rapid AF and AFL. Hemodynamic instability with verapamil was not demonstrated in this analysis, in which an overwhelming majority of patients had normal or preserved left ventricular function. Therefore, interchange between verapamil and diltiazem for acute rate control in rapidly conducted AF and AFL is a reasonable therapeutic approach.

With the increasing incidence of $\mathrm{AF}$ and a persistent shortage in the most commonly used non-dihydropyridine CCB for rate control, we believe that the results from our study will inform physicians about alternative and perhaps more optimal management of rapid AF and AFL, especially those with limited personal experience in using IV verapamil. Despite the relatively small sample in this retrospective observational study, we hope our findings might support further comparative-effectiveness investigations, ideally with randomized trials, along with mixed-methods approaches to understand physicians' prescribing behavior.

Furqan A. Rajput, $M D, M S^{1}$

Lianlian $\mathrm{Du}, \mathrm{MS}^{2}$

Richard J. Chappell, $\mathrm{PhD}^{2}$

Theodore J. Berei, PharmD ${ }^{3}$

Zachary D. Goldberger, $M D, M^{3}$

Jennifer $M$. Wright, $M D^{3}$

${ }^{1}$ Department of Medicine, University of Wisconsin School of Medicine \& Public Health,

Madison, WI, USA

${ }^{2}$ Department of Biostatistics and Medical Informatics, University of Wisconsin-Madison,

Madison, WI, USA

${ }^{3}$ Department of Medicine, Division of Cardiovascular Medicine, University of Wisconsin School of Medicine \& Public Health,

Madison, WI, USA
Corresponding Author: Furqan A. Rajput, MD, MS; Department of Medicine, University of Wisconsin School of Medicine \& Public HealthMadison, WI, USA (e-mail: frajput@wisc.edu).

\section{Compliance with Ethical Standards:}

The University of Wisconsin-Madison Institutional Review Board approved this retrospective study.

Conflict of Interest: The authors declare that they do not have a conflict of interest.

\section{REFERENCES}

1. January CT, Wann LS, Alpert JS, Calkins H, Cigarroa JE, Cleveland JC, Jr., et al. 2014 AHA/ACC/HRS guideline for the management of patients with atrial fibrillation: a report of the American College of Cardiology/ American Heart Association Task Force on Practice Guidelines and the Heart Rhythm Society. J Am Coll Cardiol 2014;64(21):e1-76. doi:https:// doi.org/10.1016/j.jacc.2014.03.022

2. Rogenstein C, Kelly AM, Mason S, Schneider S, Lang E, Clement CM, et al. An international view of how recent-onset atrial fibrillation is treated in the emergency department. Acad Emerg Med. 2012;19(11):1255-60. doi:https://doi.org/10.1111/acem.12016

3. U.S. Food and Drug Administration. Current and resolved drug shortages and discontinuations reported to fda. 2019, May 08. https://www. accessdata.fda.gov/scripts/drugshortages/dsp_ActiveIngredientDetails. cfm?AI=Diltiazem Hydrochloride\&st=c\&tab=tabs -1 .

4. Fromm C, Suau SJ, Cohen V, Likourezos A, Jellinek-Cohen S, Rose J, et al. Diltiazem vs. Metoprolol in the Management of Atrial Fibrillation or Flutter with Rapid Ventricular Rate in the Emergency Department. J Emerg Med. 2015;49(2):175-82. doi:https://doi.org/10.1016/j.jemermed. 2015.01.014

5. Salerno DM, Dias VC, Kleiger RE, Tschida VH, Sung RJ, Sami M, et al Efficacy and safety of intravenous diltiazem for treatment of atrial fibrillation and atrial flutter. The Diltiazem-Atrial Fibrillation/Flutter Study Group. Am J Cardiol. 1989;63(15):1046-51. doi:https://doi.org/10.1016/ 0002-9149(89)90076-3

6. Phillips BG, Gandhi AJ, Sanoski CA, Just VL, Bauman JL. Comparison of intravenous diltiazem and verapamil for the acute treatment of atrial fibrillation and atrial flutter. Pharmacotherapy. 1997;17(6):1238-45.

Publisher's Note: Springer Nature remains neutral with regard to jurisdictional claims in published maps and institutional affiliations. 